Article

\title{
Project Management in the Biotech Context: Exploring the Interrelation between Maturity and Sustainable Project Management
}

\author{
José Magano ${ }^{1,2, * \mathbb{C}}$, Cláudia Sousa Silva ${ }^{3}\left[\right.$ and Micaela Martins ${ }^{4}$ \\ 1 Research Center in Business and Economics (CICEE), Universidade Autónoma de Lisboa, Rua Sta, Marta 47, \\ 5 Andar, 1150-293 Lisboa, Portugal \\ 2 Institute of Business and Tourism Sciences, Rua de Cedofeita, 285, 4050-180 Porto, Portugal \\ 3 GOVCOPP, Department of Economics, Management, Industrial Engineering Industrial and Tourism, \\ University of Aveiro, 3810-193 Aveiro, Portugal; claudia.margarida@ua.pt \\ 4 Department of Economics, Management, Industrial Engineering Industrial and Tourism, University of Aveiro, \\ 3810-193 Aveiro, Portugal; micaelamartins@ua.pt \\ * Correspondence: jmagano@iscet.pt
}

Citation: Magano, J.; Sousa Silva, C.; Martins, M. Project Management in the Biotech Context: Exploring the Interrelation between Maturity and Sustainable Project Management. Sustainability 2021, 13, 12090. https://doi.org/10.3390/ su132112090

Academic Editor: Nicholas Chileshe

Received: 19 September 2021

Accepted: 26 October 2021

Published: 2 November 2021

Publisher's Note: MDPI stays neutral with regard to jurisdictional claims in published maps and institutional affiliations.

Copyright: (c) 2021 by the authors. Licensee MDPI, Basel, Switzerland. This article is an open access article distributed under the terms and conditions of the Creative Commons Attribution (CC BY) license (https:/ / creativecommons.org/licenses/by/ $4.0 /)$.

\begin{abstract}
Biotechnology is an emerging and increasingly important sector in the current context. As the number of biotech projects grows, so does the need to establish processes to improve project management effectiveness and project success, including assessing their impacts (positive and negative) on the Sustainable Development Goal (SDGs). This broader approach opens the door to developing a new project management (PM) paradigm designated by sustainable project management (SPM). However, there is a need for more empirical studies to understand how sustainability can be integrated into project management. This research is based on the proposition that PM maturity could lead to incorporating sustainability in PM. No research studies are reported in the literature exploring this interrelationship between maturity and sustainable project management; such is this study's purpose and originality. The study applies Kerzner's Level 3 PM maturity model on a sample of 96 biotech companies in Portugal through a questionnaire that addressed project managers and team members. The findings suggest that the process of integrating sustainability into PM should follow these steps: (1) perform an early PM maturity diagnosis to identify the company's most and least dominated areas; (2) identify the strengths and weaknesses that impact the integration of sustainability into project management practices; (3) develop a customized and adjusted action plan to integrate sustainability in PM. The study's main contribution relies on understanding how sustainability can be integrated into project management, explaining the role of maturity assessment in this process. In addition, it characterizes the biotech industry projects concerning the linkage between PM maturity and sustainability and provides recommendations that may contribute to the companies' development towards sustainable project management.
\end{abstract}

Keywords: project management; biotechnology; maturity; sustainability

\section{Introduction}

A generally recognized definition of biotechnology is the "application of science and technology to living organisms, as well as parts, products and models thereof, to alter living or non-living materials for the production of knowledge, goods, and services" [1] Currently, biotechnology mainly targets medicine, developing new treatment options for rare and complex diseases and genetic tests to better identify inherited diseases [2]. Biotechnology is growing fast, driven not only by ongoing events, such as the COVID19 pandemic, but also by stronger financial backing [3]. Nevertheless, other fields of biotechnology include agriculture, forestry and fishery food, environmental science, and alternative energy, such as biofuels and bioenergy [4]. 
According to Kostecki [5], the global biotechnology market value will reach 729 billion USD by 2025 [3]. A report from P-Bio, the Portuguese Association of Bioindustry Companies [6], reveals that there were 65 biotechnology companies in Portugal in 2014, generating a global turnover of 30.5 million euros and employing 478 people, of which over $60 \%$ significantly qualified. Portugal was placed at the 14 th position, contributing 0.39 percent of the total biotechnology patent publications in the EU and registering 407 patents (or 5.7 percent of all publications in Portugal) in the 2006-2014 period [6].

A significant trend in the industry is the emerging advanced computing technology, such as machine learning and artificial intelligence (AI) [2,5]. Another relevant trend is organizational arrangements over shared resources (e.g., material, digital, or both) in the shape of collaborative platforms, which the Organization for Economic Co-operation and Development (OECD) encourages (OECD, 2021).

Under such a context, where there is a need for employing the most advanced technologies and the best methods for controlling resources, project management is of paramount importance. In 2020, for instance, one could acknowledge an impressive usage of agile methodologies in biopharma and the health industry working on COVID-19 vaccines; the biotech companies quickly reacted to changes, rather than following a plan aligned with agile principles, developing mRNA solutions and thus boosting the market process [5]. Nevertheless, biotechnology is still unexplored by agile and hybrid management methodologies [7].

As the number of projects undertaken by biotech companies grows, so does the need to establish processes to improve project management effectiveness and project success [8]. However, project success cannot be measured only based on the iron triangle criteria (budget, quality, time). It is necessary to include the assessment of their impacts (positive and negative) on the sustainable development goal (SDGs), including the three triple bottom line vectors (economic, environmental and social) [9-11]. It is necessary to evolve project management processes by integrating sustainability, promoting a paradigm shift from a predictive control approach focused on processes and deliverables to a more complex, flexible, and timely approach to current challenges [12]. Still, the principles and policies of sustainability are challenging to integrate into project management systems [13], namely social and environmental dimensions [14].

According to Dubois and Silvius [15], projects are paramount in the transition of businesses towards more sustainable practices, which implies reconsidering how projects are planned, organized, and run. This sustainability view is appearing in the literature as sustainable project management (SPM). However, despite the interest in the topic, a gap is observed between the literature and what is carried out in practice [15]; there is the need for more empirical studies to understand how sustainability can be integrated into project management [16,17].

To summarize, companies, specifically biotech companies, given their importance in the current context, need to improve project success and evolve towards the SPM paradigm. The organizations' ability to improve projects' effectiveness and continuously improve project management methods to meet current needs is related to project management maturity (PMM) since a higher level of maturity indicates better performance in project management, allowing an organization "to raise awareness for potential development" [18-20]. Furthermore, it allows to identify and analyze the strengths and weaknesses of the management processes and methods and allows the comparison between organizations and the current market challenges [21].

This research is supported by a proposition that defending that PM maturity could facilitate incorporating sustainability in PM.

To the best of the authors' knowledge, there are no published works on project management maturity and sustainability in the biotech industry. Given the necessity for more empirical studies to understand how sustainability can be integrated into project management, this research seeks to: 
- contribute to a better understanding of the integration process of sustainability into $\mathrm{PM}$ in the biotech industry;

- interrelate SPM with PMM, enhancing the role of maturity in the integration process of sustainability into PM;

- identify the strengths and weaknesses that may facilitate or impede the integration of sustainability into PM;

- $\quad$ suggest recommendations for improving the integration of sustainability into PM.

As such, a sample of 96 companies operating in Portugal that involve biotech processes in their projects was studied through a questionnaire addressed to project managers and team members with Kerzner's Project Management Maturity Model diagnosis tool.

The remainder of the article is organized as follows. Section 2 puts forward a literature review covering the concepts, issues, and trends of sustainable project management and describing PM maturity models as tools to diagnose companies' PM maturity (describing, specifically, Kerzner's Project Management Maturity Model). Section 3 describes the methodology and characterizes the sample, while Section 4 presents the study's results. Section 5 discusses those results and, finally, Section 6 presents the conclusions and future research lines.

\section{Literature Review}

\subsection{Sustainable Project Management}

There has been a growing body of literature that addresses the relationship between project management and sustainability, suggesting that the integration of sustainability considerations into project management is essential for sustainable projects [22] and for increasing organizational value, reducing risk, improving project outcomes, and strengthening competitive advantage [23]. Embodying sustainability practices into project management can contribute to project success [24,25]. What defines success, however, has been changing as the field of project management matures [26], evolving from the iron triangle dimensions (cost, time, and scope) to making a greater effort to address the triple bottom line (TBL) dimensions into each project and ensure a sustainable way of life for future generations [27]. Earlier definitions of sustainable project management (SPM) highlighted the environmental aspects of project management, such as limiting resource usage and waste by projects (e.g., [28,29]). Considering the TBL dimensions [30], subsequent research on sustainability in project management has had an unbalanced perspective [16]. Therefore, a project is sustainable when it abets improvements in the environment, social integration, and social economy while maintaining cost, time, quality, and effort within an adequate range [31]. Silvius and Schipper [32] provide a more comprehensive definition of SPM: "Sustainable Project Management is the planning, monitoring and controlling of project delivery and support processes, with consideration of the environmental, economic and social aspects of the life-cycle of the project's resources, processes, deliverables, and effects, aimed at realizing benefits for stakeholders, and performed in a transparent, fair and ethical way that includes proactive stakeholder participation". This definition is notably in line with the TBL concept, and also includes life-cycle orientation, stakeholder orientation [33], and ethics into project management.

According to Marnewick et al. [34], the relationship of project management and sustainability can be looked at from two perspectives: sustainability by the project, associated with the sustainability of the deliverable the project generates, and sustainability of the project, related to the sustainability of the project's management processes and delivery. Labuschange and Brent [35] established a connection between both views, claiming that sustainability implies a complete life-cycle approach, considering that sustainability in the project must be extended to the sustainability of its deliverables and effects beyond the project itself.

Achieving sustainable project management implies following several principles [16,23,25], namely commitment and accountability, guaranteeing the rights of the critical stakeholders, ethics and decision-making, integration and transparency, enhancement of natural 
resources, social and ecological equity, and economic prosperity. Furthermore, project managers must use a variety of skills [36,37], including decision-making. Indeed, sustainability entails the influential consideration of human and environmental aspects in decision-making in any developed economic activity [38], thus impacting project management at the project manager level [39]. In this regard, Mishra et al. [40] identify ethics as the fourth dimension of project management by adding it to the project management iron triangle and conclude that it will contribute to sustainable project management. Earlier studies found that the project manager's behavior towards sustainability is most of all a personal trait [22,41,42], which implies that, to a certain extent, the human factor is decisive to embedding sustainability in project management. Many decisions at the project level are subsequently of a moral nature, relying on the project manager's competence and behavior toward sustainability [42]. A study by Sabini and Alderman [43] showed that when tensions arise over sustainable objectives (temporality of objectives, organisational barriers, lack of control), they are dealt with only when tied to a business case for sustainability, suggesting project managers are often exposed to paradoxical situations. Moreover, in the absence of an appropriate higher-level plan or when there are weaknesses in the ability to transfer strategic orientations to the project level, a strategic perspective can be assumed at the project level [44]. The motivation to consider sustainability in projects and project management should not be a responsibility of the project manager alone [39]; sustainability should involve proactive stakeholder participation [45] through effective communication and consensus [23]. However, there is still a lack of methods and techniques that facilitate sustainability assessment and decision-making at the project level [46] and that provide alternative approaches that overcome the inherent tensions that the concept of sustainability brings into the project management context [43].

Corder and colleagues [13] refer to the need for suitable systematic frameworks to allow for sustainability-aligned initiatives proper consideration, the assessment of sustainability in project management systems, or the analysis of problems deriving from the use of sustainability indicators. The overall idea of a framework is to provide a standard instrument to drive the project to translate sustainability principles and thinking into project management operating practices and design [13,39], thus dealing with the impact of sustainability at the project level. Several authors have published frameworks and methods to this end; among others, Corder et al. introduced the SUStainable OPerations $\left(\mathrm{SUSOP}^{\circledR}\right)$ ) for the mining industry [13,47]; MarcelinoSádaba et al. described a conceptual framework to manage sustainable projects based on four dimensions-products, processes, organisations, and managers [38]; Férnadez-Sánchez and Rodriguez-López developed methods to identify sustainability indicators working from ISO 21929-1 and risk management standards in construction projects [31]; Labuscahnge and Brent described a framework instrument for the social assessment of projects and social impacts based on the project life cycle [35,48]; Morris et al. proposed the Local Government Project Management Maturity Model (LGPM3). Another approach towards an assessment instrument for sustainability in project management is organisational maturity models [17].

\subsection{Project Management Maturity Models}

An organizational maturity model can help assess and foster sustainability in project management $[8,17]$. Andersen and Jessen define maturity as "the optimized ability and capability of a system or an organization versus its intended goals, and it is a state in which an organization is in a perfect condition to pursue its objectives" [49]. An organizational maturity model is usually characterized by a number of levels, describing stages (or levels) and maturation paths [17]. Maturity levels are associated with a group of capabilities that describe progressively greater orders of consistency, visibility, and control within the organization and essentially describe the ideal progression toward desired improvement [50].

Existing maturity models vary between process-focused and organization-oriented [8], being sometimes seen as too bureaucratic, too narrow in focus, and ignoring the organizational context [51]. To overcome such criticisms, industry-specific maturity models 
have been developed in recent years $[8,50]$. They can be descriptive, prescriptive, or comparative [17]. A descriptive maturity model assesses the current capabilities of an organization; a prescriptive one adds the identification of desirable maturity levels and suggests improvement actions; a comparative model allows one to assess the maturity of a wide range of organizations, comparing an organization's practices against best practices or those used by competitors.

Project management maturity can be understood as "the ongoing process of periodically identifying, measuring, implementing, and reassessing continuous improvement opportunities in the project delivery system and supporting infrastructure such that the organization can improve its ability to meet its strategic goals and objectives" [52]. The concept of project management maturity has been developed into a standard by the Project Management Institute (PMI) since 1998, having then created the model maturity of organizational project management (known as OPM3) to enable organizations to fill in the gap between organizational strategy and successful projects. Afterward, different researchers and institutions developed project management maturity models (PMMM) based on best practices (e.g., [17,51-55]).

A PMMM contributes with several benefits: identifies the organization's strengths and weaknesses and opportunities for continuous improvements, provides benchmarking information, compares results against project management, industry, and world-class standards, recognizes that project management is of a strategic nature and allows a company to focus on competitive advantage opportunities, improve its performance indicators, and identify metrics that will measure both tangible and intangible asset growth [52]. There are more than thirty PMMMs available in the marketplace [52], however, an organization should carefully select and customize the most suitable model.

\subsection{Kerzner's Project Management Maturity Model (PMMM)-Singular Methodology}

Kerzner's PMMM has five levels of maturity [52]: Level 1-“Common Language”; Level 2-“Common Processes"; Level 3-“Singular Methodology"; Level 4-“Benchmarking”; Level 5-"Continuous Improvement. As this research is more focused on corporate culture, Level 3 of Kerzner's PMMM was selected as the instrument to support the empirical study; thus, this section addresses this level only to describe and understand better the dimensions it encompasses.

The singular methodology of Kerzner's PMMM [52] defends a single method focused on project management, making the control of existing processes more straightforward than in a context in which there are multiple methodologies. Furthermore, it allows one to assess the recognition, synergies, and process control to develop a unique methodology, helping one perceive the organization's level of commitment to project management. This level consists of six axes building the "Hexagon of Excellence": integrated processes, culture, management support, informal project management, training and education, and behavioral excellence [52].

Each axis will allow one to understand better the project management (PM) domain in different organizations:

- Integrated process: bet on the integration of PM processes in a standardized methodology. As PM maturity increases, the organization progressively integrates PM processes into a single method, leading to more efficient performance. Considering the current context, Kerzner argues that this integration should include the following processes: project management, total quality management, risk management, change management, and concurrent engineering [52].

- Culture: this integration requires a culture that supports the PM approach, becoming a collaborative culture accepted by all.

- Management support: management support at all levels is necessary for this singular methodology to be consolidated. This support is achieved by sharing responsibility for the project's success between project managers and line management, where deliverables are negotiated. Line managers create a context of trust that supports 
employees' decisions related to their functional area. The project manager has the responsibility to help the line manager develop alternative plans in risk situations. The relationship between the project manager and senior management is equally important, as well as with the executive management, including the sponsor. A culture of empowerment and decentralization is favored, fostering decision-making capacity.

- Informal project management: the unique methodology is based more on guidelines and checklists than on an exhaustive and rigid PM process supported by policies and procedures. Paperwork is minimized given the associated high costs and time. For this, the organization must develop its processes of communication, cooperation, trust, and teamwork. There is a strong investment in visual management tools, such as color traffic lights.

- Training and education: the financial return on investment in PM training is expected, being accounted for either in quantitative benefits (shorter product development time, higher profit margins, fewer costs people) or qualitative benefits (visibility, higher morale, customer relationship, involvement, decreased number of conflicts comings up to the senior levels). Training programs cannot be considered as a set of randomly planned actions.

- Behavioral excellence: behavioral training programs are developed to improve PM skills, namely motivation, leadership, and teamwork.

\section{Materials and Methods}

\subsection{Instrument}

Kerzner's PMMM Level 3 [52] was adopted and structured in a questionnaire with 42 multiple-choice questions as the assessment instrument of this study. Each axis of the Excellence Hexagon has seven questions and a maximum score of 35 points-therefore, a total score of 210 points. Each axis score was calculated by consulting the scoring grid [52], and the total punctuation was interpreted according to Table 1.

Table 1. Kerzner's PMMM classes of maturity Level 3 [52].

\begin{tabular}{|c|c|}
\hline Points & Interpretation \\
\hline $\begin{array}{c}\text { Class } 1 \\
169-210\end{array}$ & $\begin{array}{l}\text { "Your company compares very well to the companies discussed in this text. You are on the right track for excellence, } \\
\text { assuming that you have not achieved it yet. Continuous improvement will occur." }\end{array}$ \\
\hline $\begin{array}{c}\text { Class } 2 \\
147-168\end{array}$ & $\begin{array}{l}\text { "Your company is going in the right direction, but more work is still needed. Project management is not totally } \\
\text { perceived as a profession. It is also possible that your organization simply does not fully understand project } \\
\text { management. Emphasis is probably more toward being non-project-driven than project-driven." }\end{array}$ \\
\hline $\begin{array}{l}\text { Class } 3 \\
80-146\end{array}$ & $\begin{array}{l}\text { "The company is probably just providing lip service to project management. Support is minimal. The company } \\
\text { believes that it is the right thing to do but has not figured out the true benefits or what they, the executives, should } \\
\text { be doing. The company is still a functional organization." }\end{array}$ \\
\hline $\begin{array}{c}\text { Class } 4 \\
\text { Below } 79\end{array}$ & $\begin{array}{l}\text { "The company has no understanding of project management, nor does it appear that the company wishes to change. } \\
\text { Line managers want to maintain their existing power base and may feel threatened by project management." }\end{array}$ \\
\hline
\end{tabular}

\subsection{Procedures}

As designed by Kerzner [52], the questionnaire was translated to Portuguese and back-translated to English. It was then sent by e-mail to 250 companies located in Portugal whose projects integrate biotech processes and addressed to project managers (one per company). Informed consent was obtained from all subjects involved in the study. A hundred responses were obtained, of which 96 were validated; the respondents were project managers and, in 8 companies, senior team members.

\subsection{Data Analysis}

Data obtained for 2.5 months were analyzed using Excel and IBM SPSS Statistics 27 software. It was applied descriptive statistics, inferential statistics, and correlational studies. The inferential analysis was supported at a significant level of at least 0.05 . An 
independent sample $t$-test was used to compare the means between groups. A Pearson product correlation was determined for a bivariate association between the six axes of the hexagon of excellence for interpreting the effect size (large effect $r \geq 0.50$, medium effect $0.30 \leq r<0.50$, and small effect $0.10 \leq r<0.30$ ) [56]. The reliability of the measurement scale was analyzed through the internal consistency coefficient Cronbach alpha, obtaining 0.876 (for the 42 questions). Alpha values greater than 0.700 indicate good internal consistency and that the items are consistent in measuring the same construct-in this case, the maturity of the organization [57]. The validity of Kerzner's scale is supported by other peer-reviewed studies $[58,59]$.

\subsection{Sample Characterization}

Tables 2 and 3 characterize, respectively, the participating organizations and professionals who answered the questionnaire.

Table 2. Main Organization Characteristics.

\begin{tabular}{ll}
\hline \multicolumn{1}{c}{ Characteristic } & \multicolumn{1}{c}{ Organization } \\
\hline Size & Micro company, 53.6\%; Small company, 21.7\%; Medium company, 4.1\%; Large Company, 20.6\%. \\
\hline Market experience (years) & $(1-10), 49.5 \% ;(10-20), 24.7 \% ;(20-30), 8.3 \% ;(30-40), 5.2 \% ;>40,12.4 \%$ \\
\hline & Environmental and Industry, 26.0\%; Plant biotechnology, 20.8\%; Molecular and cellular, 16.7\%; \\
Biotechnological Area & Medical devices, 8.3\%; Laboratory research and clinical analysis, 7.3\%; Bioinformatics, \\
& Bioengineering, Food Biotechnology and Pharmaceuticals, 4.2\% \\
\hline
\end{tabular}

Source: Own work.

Table 3. Main PM Professionals Characteristics.

\begin{tabular}{ll}
\hline \multicolumn{1}{c}{ Characteristic } & \multicolumn{1}{c}{ Professionals } \\
\hline Age (years) & $(18-25), 16.5 \% ;(26-35), 42.3 \% ;(36-45), 24.7 \% ;(46-55), 16.5 \%$ \\
\hline Experience in company (years) & $<1,20.6 \% ;(1-5), 24.7 \% ;(5-10), 25.8 \% ;(10-15), 4.1 \% ;>15,24.7 \%$ \\
\hline Main function in PM & Project manager, 45.4\%; Coordinator, 37.1\%; Team member, 17.5\% \\
\hline $\begin{array}{l}\text { Project Management experience } \\
\text { (years) }\end{array}$ & $<1,8.3 \% ;(1-5), 38.1 \% ;(5-10), 16.5 \% ;(10-15), 8.3 \% ;>15,16.5 \% ;$ none, 12.4\% \\
\hline Academic literacy & Graduated, 16.5\%; M.Sc., 37.1\%; Ph.D., 34.0\%; other, 12.4\% \\
\hline PM Certification & None, 86.6\%; PMP (Project Management Professional), 9.3\%; Ongoing PMP, 4.1\% \\
\hline PM training in Education Programs & No, 55.9\%; Yes, 44.1\% \\
\hline
\end{tabular}

Source: Own work.

The companies that participated in the study act in diversified industry areas. More than half are micro or small companies and established in the market for less than ten years, signaling the emergence of the industry.

The professionals' sample is multigenerational, as different age groups were significantly present. There was also a balanced distribution between less and more experienced professionals. Almost $50 \%$ of the participants are enrolled as project managers and, despite their high academic literacy, more than half had no PM in their education programs.

\section{Results}

The results section starts with these companies' level 3 maturity score (singular methodology), highlighting the predominant organizational characteristics in each of the four classes at this level. Subsequently, an overall analysis of the hexagon of excellence's six axes is carried out, further detailed by maturity class. Finally, this section presents some statistical tests to understand which characteristics most impact maturity level 3 , singular methodology. 


\subsection{Results Level 3-Singular Methodology}

Figure 1 shows that none of the 96 companies had yet completed maturity level 3 (169-210 score), and 12 had no knowledge of the PM practices, obtaining a score below 79. Surprisingly, almost $67 \%$ of the companies that belonged to this last group were large companies, and the same percentage indicates that they had not yet adopted a standardized PM methodology.

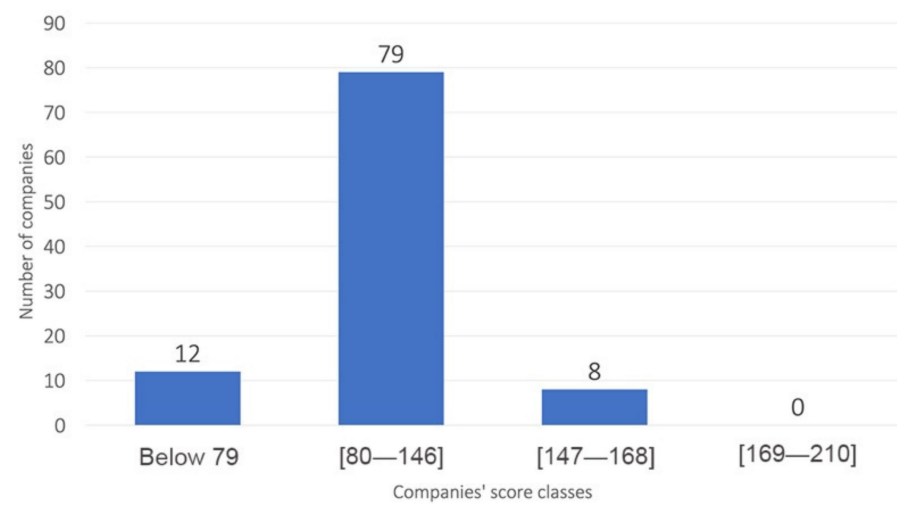

Figure 1. The number of companies per score class Source: Own work.

As depicted in Figure 1, eight organizations were in the (147-168) score class. All of them had been in the market for more than ten years; moreover, $50 \%$ were micro companies, and the remaining were large corporations. The majority (about $80 \%$ ) of participating companies were in the range of 80 to 146 points, which indicates that, despite recognizing the PM benefits, they were still organized as a functional structure. Since this class has most companies, it was decided to deepen the analysis further, as shown in Figure 2.

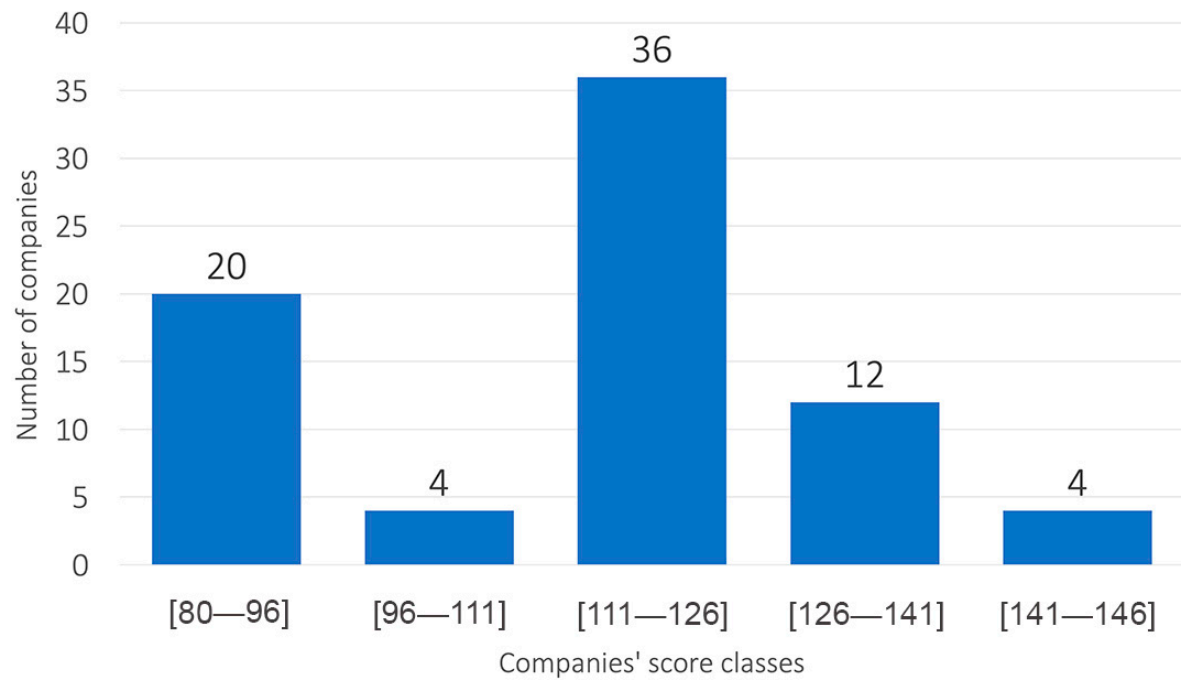

Figure 2. 80-146 points class histogram breakdown Source: Own work.

Most companies were positioned between this class's middle and upper limits, revealing some PM progression trends and the intention to consolidate PM knowledge and good practices.

\subsection{Hexagon of Excellence}

Since the assessment of maturity level 3 integrates the six axes of the hexagon of excellence, the global results (for the 96 companies of the sample) are shown in Figure 3 and Table 4. 


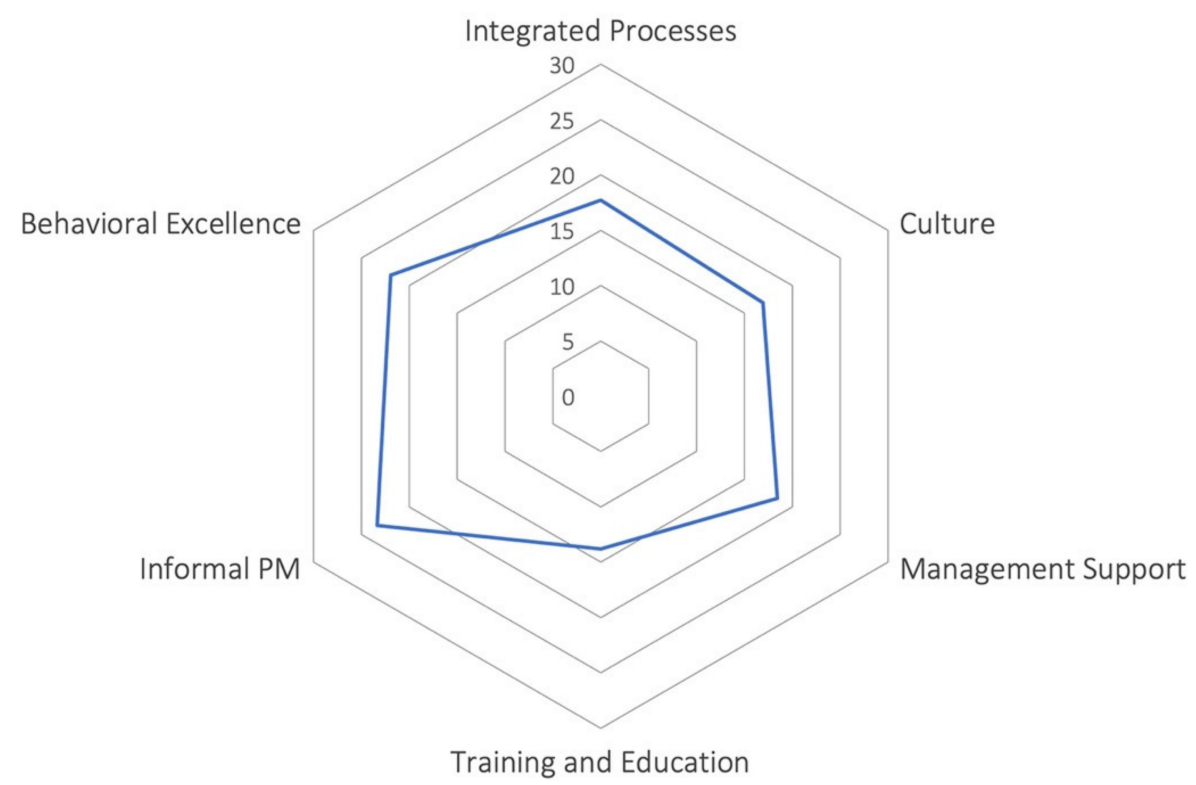

Figure 3. Hexagon of excellence-results for the 96 companies (Source: Own work.).

Table 4. Hexagon of excellence-results of 96 companies.

\begin{tabular}{cccc}
\hline Axis & Mean & $\begin{array}{c}\text { Standard } \\
\text { Deviation (SD) }\end{array}$ & $\begin{array}{c}\text { Percent of Maximum } \\
\text { Score }\end{array}$ \\
\hline Integrated Processes & 17.7 & 10.5 & 50.6 \\
Culture & 16.9 & 7.2 & 48.3 \\
Management Support & 18.4 & 3.6 & 52.6 \\
Training and & 13.8 & 6.8 & 39.4 \\
Education & 23.3 & 3.7 & 66.7 \\
Informal PM & 21.9 & 3.8 & 62.7 \\
Behavioral Excellence & & & \\
\hline
\end{tabular}

Source: Own work.

As can be seen, from a global perspective of the sample, only the informal PM and behavioral excellence axes present an average value greater than $60 \%$ of the maximum possible. The informal PM axis stood out with the highest value with a scoring average of 23.3 points. The lowest value occurs with training and education (13.8 points), only 39\% of the maximum value. Once the sample includes companies integrated into different classes, Table 5 presents more detailed results by class regarding the 6 axes.

Table 5. Hexagon of excellence-96 companies' mean results by class.

\begin{tabular}{cccccccc}
\hline Class & Int. Pro. & Culture & Man. Support & $\begin{array}{c}\text { Train. } \\
\text { Education }\end{array}$ & Informal PM & $\begin{array}{c}\text { Behavioral } \\
\text { Excellence }\end{array}$ & $\begin{array}{c}\text { SD } \\
\text { Class 4, below 79 }\end{array}$ \\
Class 3, 80-146 & 3.3 & 6.0 & 17.7 & 6.7 & 17.7 & 15.3 & 6.5 \\
Class 2, 147-168 & 18.7 & 17.5 & 18.1 & 13.6 & 23.9 & 22.4 & 3.7 \\
\hline
\end{tabular}

Source: Own work.

Companies that belong to class 4 and, therefore, are far from understanding the PM value demonstrated great difficulty in integrating processes, creating a PM culture, and developing training programs capable of leveraging the PM skills.

In the range of $80-146$ points ( $80 \%$ of the sample), the least dominated axis is training and education (mean $=13.6$ ), followed by culture and management support. However, these organizations showed some domain in informal PM, as they achieved $68 \%$ of the maximum score. 
In an opposite position, eight companies are positioned in the 147-168-point class, where PM maturity results from a commitment to process integration (mean $=30$, approximately $86 \%$ of the maximum score) and promoting a culture leading to PM development (mean $=27.5$ ). Moreover, those companies have been in the market for over ten years, indicating that they are not recent organizations; about 50 percent are micro-companies. This information arouses the interest in better understanding these characteristics (market experience and size) at this maturity level. So, a comparative study of the means was carried out using the $t$-test (Table 6).

Table 6. A $t$-test comparative maturity study considering market experience and size.

\begin{tabular}{cccc}
\hline Groups & N & Mean & $p$-Value \\
\hline Market experience of up to 10 years & 48 & 109.3 & \multirow{2}{*}{0.304} \\
Market experience for over 10 years & 48 & 114.9 & $p$-Value \\
\hline Groups & $\mathrm{N}$ & Mean & \multirow{2}{*}{0.878} \\
\hline Micro companies & 52 & 111.7 & \\
\hline
\end{tabular}

Source: Own work.

Based on the $p$-value results, one cannot affirm that companies that have been in the market for a longer time have a statistically significant score maturity mean different from the other companies; the same conclusion applies concerning the company's size. However, companies in class 2 have a balanced domain of the six axes, as shown by the mean's standard deviation, decreasing as the maturity class evolves. So, will other characteristics, (namely management, culture, training, leadership, and structure) play a more determining role in maturity? To deepen this analysis, a correlation study between those six axes is presented in Table 7.

Table 7. Pearson correlation considering the 96 companies.

\begin{tabular}{ccccccc}
\hline & $\begin{array}{c}\text { Integrated } \\
\text { Processes }\end{array}$ & Culture & $\begin{array}{c}\text { Management } \\
\text { Support }\end{array}$ & $\begin{array}{c}\text { Training } \\
\text { Education }\end{array}$ & $\begin{array}{c}\text { Informal } \\
\text { PM }\end{array}$ & $\begin{array}{c}\text { Behavioral } \\
\text { Excellence }\end{array}$ \\
\hline Integrated Processes & - & $0.567^{* *}$ & $0.350^{* *}$ & $0.447^{* *}$ & $0.581^{* *}$ & $0.338^{* *}$ \\
Culture & - & - & $0.427^{* *}$ & $0.723^{* *}$ & $0.642^{* *}$ & $0.564^{* *}$ \\
Management Support & - & - & - & $0.274^{* *}$ & $0.405^{* *}$ & 0.194 \\
Training and Education & - & - & - & - & $0.478^{* *}$ & $0.569^{* *}$ \\
Informal PM & - & - & - & - & - & $0.557^{* *}$ \\
\hline
\end{tabular}

** Correlation is significant at the 0.01 level (2-tailed) (Source: Own work).

Considering the table above, several significant correlations were identified between the different axes. Furthermore, the culture axis stands out in this analysis, as it presents a correlation with a large effect $(r \geq 0.50)$ with almost all other axes, except with management support. Training education also stands out, revealing a strong interrelationship with behavioral excellence and culture. However, in these two axes, the sample revealed more weaknesses, obtaining the lowest average score, which is not a good indicator.

\section{Discussion}

\subsection{Are Biotech Companies Prepared to Integrate Sustainability into PM?}

The main research focus was exploring the interconnection of sustainability in PM and maturity. Effective integration of sustainability in PM requires some consolidation, strategy, culture, and widespread standardization of PM methods. Level 3, singular methodology of Kerzner's PMMM is an instrument that can measure the standardization of the PM processes implementation at all management levels to consolidate PM organizational knowledge. 
According to the results presented in Section 4, these companies show a premature level of PM singular methodology, as around $80 \%$ of the sample obtained a score between 80 and 146 points (class 3 ). However, $65 \%$ are between the mean and the maximum value of this class, revealing progression in the right direction.

In sum, most participating companies have not yet integrated PM processes in a consolidated way. As a result, they do not have the necessary organizational culture to standardize PM methodologies at all management levels, from the sponsor, executive management, project management, and line management. Also, the training and education axis presents the lowest score in this sample. These results raise some concern once culture and training education reveals a strong interrelationship with almost all other axes, having a proactive role in improving PMM.

On the other hand, the informal PM and behavioral excellence axes are positive points, presenting an average value greater than $60 \%$ of the maximum possible.

Therefore, these initial PMM diagnoses should be accounted for in the decision to integrate sustainability in PM, being recommended as the initial step in the integration process. To deepen the sample's PMM, the following point portrait the main weaknesses and strengths to understand better how it can impede or facilitate the integration of sustainability in project management.

\subsection{PM Maturity Diagnosis: Weaknesses and Strengths in (Singular Methodology)}

Considering the hexagon of excellence evaluation $(\mathrm{N}=96)$, there were differences in the domain of the respective axes, revealing different PM knowledge levels of these companies. Table 8 discusses the positive and negative points by axis, organized by decreasing importance.

Table 8. Positive and negative points by axis of the hexagon of excellence.

\begin{tabular}{ccc}
\hline $\begin{array}{c}\text { Average Score } \\
\text { by Axis }\end{array}$ & Positive Points & Negative Points \\
\hline
\end{tabular}

91.7\% assume that the organization's culture is characterized by informal project management based on trust, communication, and cooperation.

1. Informal PM (mean: 23.33) Good predisposition to reduce paperwork, both in reporting time $(54.2 \%$ use between 5 to $10 \%$ in reporting) and in meetings (50\% meetings last between 30 to $60 \mathrm{~min}$ ).

$\begin{array}{ll}\text { 2. Behavioral } & 50.0 \% \text { recognize that the performance assessment of } \\ \text { Excellence } & \text { the project team members must be done by both the } \\ \text { (mean: } 21.92) & \text { operational manager and the project manager. }\end{array}$
operational manager and the project manager.

3. Management
Support
(mean: 18.42)

\section{Integrated} Processes (mean: 17.71)

$62.5 \%$ of line managers assume responsibility for project activities related to their area.

$58.3 \%$ refer that risk management follows a multi-factor strategy based on a combination of financial, technical, and scheduling risks.

The Total Quality Management-TQM process is the most integrated in PM (33.3\%).

Lack of awareness of the costs associated with project management bureaucracy $(75 \%$ have no idea of the associated costs).

Great emphasis still on technical knowledge (41.7\%) Only $33.3 \%$ recognize risk management and the integration of business knowledge as the most important skills in the 21st century.

Project managers do not show practices in training teams based on results and not on people.

Only 25\% report that they integrate all processes Only $7.3 \%$ integrate only risk management and simultaneous engineering.

Only $4.0 \%$ indicate that risk management is supported by a standardized methodology.

Only $12.5 \%$ admit benchmarking practices that result in changes in PM processes.

$\begin{array}{ll}\begin{array}{l}\text { 5. Culture } \\ \text { (mean 16.92) }\end{array} & \begin{array}{l}41.7 \% \text { admit a culture of change at any stage of the } \\ \text { project life cycle, using change management processes }\end{array}\end{array}$

$79.2 \%$ state that the organization does not provide training courses related to morality, ethics, and good business practices and $51.1 \%$ admit that they do not have any policy in relation to morality and ethics. 
Table 8. Cont.

\begin{tabular}{|c|c|c|}
\hline $\begin{array}{l}\text { Average Score } \\
\text { by Axis }\end{array}$ & Positive Points & Negative Points \\
\hline $\begin{array}{l}\text { 6. Training and } \\
\text { Education } \\
(\text { mean } 13.79)\end{array}$ & $\begin{array}{l}62.5 \% \text { believe that training should be done to meet } \\
\text { long and short-term needs. }\end{array}$ & $\begin{array}{l}58.3 \% \text { refer that PM is a part-time job or the absence } \\
\text { of project managers in the company. } \\
70.8 \% \text { say that PM trainings are not carried out with } \\
\text { resources to case studies, where lessons learned can } \\
\text { be focused. } \\
58.3 \% \text { report that there is no participation of } \\
\text { executives in actions related to PM maturity. } \\
\text { Only } 25.0 \% \text { relate the need for a training action to its } \\
\text { Return on investment. }\end{array}$ \\
\hline
\end{tabular}

Source: Own work.

\subsection{Integrating Sustainability into PM Practices}

The analysis of Section 5.2 reveals positive aspects that are likely to contribute to integrating sustainability in project management.

Firstly, most respondents show a predisposition to reduce paperwork, a trend that reflects environmental and economic sustainability factors [17], as paper reduction means saving resources and reducing waste, impacting the environment, as well as costs and time. Subsequent reporting and meetings' duration cutback can also speed up project execution and boost efficiency. However, that implies better communication, trust, and teamwork, which are drivers for a collaborative culture that facilitates informal project management (thus, reducing project execution costs and time and relying less on rigid policies and procedures) [52,60]. Interestingly, almost all respondents assume that the organization's culture is characterized by informal project management. This inherent cooperation can be extended to internal and external stakeholders, enhancing social sustainability factors such as participation (through stakeholder engagement and better coordination and collaboration) [45] and corporate governance (e.g., simplifying reporting), in turn leading to greater project maturity.

Evolving towards better cooperation implies corporate culture adjustments and the support of the entire organization that may prove challenging but necessary to reach higher maturity levels [32,52]. Although this is a risky step, almost half of the respondents admitted a culture of change at any stage of the project life cycle, using change management processes.

Most respondents mentioned that risk management follows a multi-factor strategy based on a combination of financial, technical, and scheduling risks, while a third of the sample confirms that TQM is the most integrated process in PM. This result shows that a good deal of effort is yet to be spent to promote a stronger process integration of concurrent engineering, TQM, change, project, and risk management (improving risk management contributes to minimizing risk and economic sustainability).

The results also reveal that most respondents agree that training should meet long and short-term needs. Training and learning are social sustainability variables through which the human capital is cultivated, increasing the (economic) value of the organization's intellectual capital (competencies, knowledge, and skills) [17,25,38]. This capital is the organization's constantly renewable source of creativity and innovativeness (again, relying on the ability to change) [17]. As previously described, training materializes in quantitative and qualitative benefits, and ultimately, in added profits and behavioral excellence [52]. It is also an excellent means to strengthen project management with core competencies and skills (including risk management, business knowledge, and sustainability awareness) and the inclination to embed sustainability in PM.

The above-mentioned results are somehow evidence of the potential for integrating sustainability variables in project management practices. However, one can acknowledge existing obstacles to this integration as well in a substantial portion of the participating 
companies. For instance, the lack of awareness of project management bureaucracy costs does not encourage people to be proactive in reducing paper use and waste, impeding environmental benefits to an extent. In addition, most companies do not integrate the multiple processes in place, of which risk management seems to deserve little consideration, despite substantial recognition of its importance to modern project management $[23,27,32,61]$, and still heavily rely on isolated processes and technical skills alone.

As shown above, the cultural dimension is critical for both maturity and sustainability practices adoption. Social sustainable factors such as participation and human capital development are paramount to cultural change $[17,23,32,39]$. However, in this case, the culture axis of the excellence hexagon revealed a weak value, at the same time showing significant correlations with training, management support, informal PM, and behavioral excellence. In fact, more than half of the participants claim there is no participation of executives in actions related to PM maturity. At the same time, most refer that PM is a parttime job or, worse, there are no project managers in the company. On the other hand, over two-thirds of the participants report that the training provided does not approach aspects related to ethics and business (including general business-related practices and, to a lesser extent, return on investment) and show a lack of focus on lessons learned from completed projects. This diagnostic calls for a corporate commitment to project management at the executive, project, and line management levels and to provide appropriate training, thus creating better conditions to promote projects' sustainability and maturity.

\subsection{Customizing an Action Plan to Improve the Integration of Sustainability in PM}

The recognition of the strengths and weaknesses of the sample suggests that there are opportunities to improve project management maturity by means of integrating sustainability; also, a higher maturity degree should facilitate the integration of those sustainability aspects. In this regard, sustainability consideration and project management maturity are synergetic and provide mutual benefits. Based on previous considerations, a first recommendation to tackle such a challenge is to perform an early diagnostic to characterize the biotech companies' PM maturity level. The main strengths and weaknesses should support the companies to identify the priority areas to act aiming to integrate sustainability into PM practices. Considering this sample diagnostic, a customized action plan with several recommendations emerge from developing SPM in these companies, such as:

- Develop and implement a training program based on a project management curriculum to provide professionals with core PM competencies and skills, including ethics and sustainability.

- Promote the integration of processes, namely, project management, total quality management, risk management, change management, and concurrent engineering. Communicating the success of process integration could be a way to demonstrate the advantages of this approach across the organization.

- Develop the risk management process based on a standardized methodology and promote its integration with other PM processes; risk management is a key element of sustainability management and improves the project impacts in SDGs.

- Set the project's key performance indicators encompassing the SDGs and promote the decision based on these results.

- Formalize a good business practices code related to morality and ethics to apply in PM.

- Actively engage stakeholders in the PM processes, including the different management layers of the organization, as their participation is a sustainability variable and concurs to maturity evolvement.

- Encourage actions that contribute to materials and waste reduction and other environmental practices.

- Foster informal project management and ensure the necessary institutional support, consolidating practices that contribute to a cultural approach that overcomes any resistance to the singular PM methodology. 


\section{Conclusions}

This study's research was aimed to better understand the integration process of sustainability into PM in the biotech industry due to its emergence and importance in the current context. Under such circumstances, it is paramount that PM evolves to high maturity levels and embeds sustainability considerations into PM practices. Thus, 96 biotech companies were analyzed using a questionnaire survey based on Kerzner's Level 3 PM maturity model.

The results reflect the diversity of the cases, showing premature levels of PM singular methodology yet also progression in the right direction. Generally, the companies revealed strengths related to environmental issues (e.g., paper reduction), economic issues (reporting and meetings' duration reduction with subsequent efficiency gains, risk management, business-related aspects consideration, or processes integration), and social issues (participation, corporate governance, and human capital development). However, they also showed weaknesses, including the lack of adequate sustainability policies, poor processes integration, management support, training, and executive management engagement in actions related to project management maturity.

The other main research goal was to relate SPM with PMM enhancing the role of maturity in the integration process of sustainability in PM. Our results suggest a process with the following main steps to link maturity and sustainability:

- An early maturity diagnosis to assess if organizations are prepared to integrate sustainability in PM.

- The identification of PMM's strengths and weaknesses to understand how it can prevent or facilitate the integration of sustainability in project management.

- As each company is unique, the customization of an action plan to integrate sustainability in PM. Thus, along this path, it is necessary to create a process that simultaneously facilitates the integration of key sustainability elements and the consolidation of PM maturity.

Thereby, it is not recommended to adopt "recipe-type" integration processes without a previous PM diagnosis to identify the most and least dominated areas for integrating sustainability in PM. These research results have practical contributions once the process integration steps and recommendations could guide and expire companies' development towards SPM.

The study's originality relies on exploring this relationship in a thriving industry where no such approaches have been reported.

However, one should point some limitations. The sample size may have been one such limitation, impeding a broader picture of the biotech industry in Portugal regarding sustainability and PM maturity. Another limitation was that, though providing valuable data, the questionnaire survey may have been further complemented with personal interviews to better capture other participants' perspectives and ensure they appropriately reflected the true situation of the companies. The findings could be further explored in future studies, possibly extending the number of participants, and using other research methodologies, such as case studies and interviews, to reach a deeper and broader picture of Portugal's biotech industry regarding sustainability and PM maturity.

Author Contributions: Conceptualization, C.S.S., J.M. and M.M. Methodology, M.M., C.S.S. and J.M. Writing - original draft preparation, C.S.S. and J.M. Writing—review and editing, J.M., C.S.S. and M.M. All authors have read and agreed to the published version of the manuscript.

Funding: This research received no external funding.

Institutional Review Board Statement: Ethical review and approval were waived for this study, due to that the research does not deal with vulnerable groups or sensitive issues.

Informed Consent Statement: Informed consent was obtained from all subjects involved in the study. 
Data Availability Statement: The data presented in this study are available on request from the corresponding author. The data are not publicly available due to General Data Protection Regulation (GDPR).

Conflicts of Interest: The authors declare no conflict of interest.

\section{References}

1. OECD. A Framework for Biotechnology Statistics; Organisation for Economic Co-operation and Development: 2005. Available online: https://www.oecd.org/sti/emerging-tech/aframeworkforbiotechnologystatistics.htm (accessed on 1 September 2021).

2. Eastwood, B. 6 Trends in Biotechnology in 2021. Available online: https://www.northeastern.edu/graduate/blog/emergingbiotechnology-trends/ (accessed on 25 August 2021).

3. Carleton, S.C. Emerging Biotechnology Trends for 2021. Available online: https://www.northeastern.edu/graduate/blog/ biotechnology-trends / (accessed on 25 August 2021).

4. Wydra, S. Value chains for industrial biotechnology in the bioeconomy-innovation system analysis. Sustainability 2019, 11, 2435. [CrossRef]

5. Kostecki, A. BioTech Trends 2021. Available online: https://www.nearshore-it.eu/articles/technologies/biotech-trends-for-2021 (accessed on 1 September 2021).

6. Cerejeira, J.; Portela, M.; Sá, E. The Portuguese Biotechnology Industry: Firms, Labour Market and Innovation Indicators; Portugal's Biotechnology Industry Organization: 2016. Available online: http://p-bio.org/wp-content/uploads/2017/01/relat\%C3\%B3riofinal-dos-dados-do-setor-em-ingl\%C3\%AAs.pdf (accessed on 1 September 2021).

7. Linares, I.M.P.; Alves, M.F.R.; Tristão, R.L.; Amaral, D.C. Adherence between project management practices and environmental critical factors in biotechnology companies. Gestão Produção 2019, 26. [CrossRef]

8. Spalek, S. Establishing a Conceptual Model for Assessing Project Management Maturity in Industrial Companies. Int. J. Ind. Eng. 2015, 22, 301-313.

9. Ebbesen, J.B.; Hope, A. Re-imagining the iron triangle: Embedding sustainability into project constraints. PM World J. $2013,2$.

10. Haugan, G.T. The New Triple Constraints for Sustainable Projects, Programs, and Portfolios; CRC Press: Boca Raton, FL, USA, 2013.

11. Silvius, A.; Nedeski, S. Sustainability in IS projects: A case study. Commun. IIMA 2011, 11, 1.

12. Carboni, J.; Reeson, M. The advent of the Sustainability Management Plan: Pratical activities that are long overdue. In Proceedings of the 26th IPMA World Congress, Crete, Greece, 2012; pp. 1113-1117.

13. Corder, G.; McLellan, B.; Green, S. Delivering solutions for resource conservation and recycling into project management systems through SUSOP ${ }^{\circledR}$. Miner. Eng. 2012, 29, 47-57. [CrossRef]

14. Sánchez, M.A. Integrating sustainability issues into project management. J. Clean. Prod. 2015, 96, 319-330. [CrossRef]

15. Dubois, O.; Silvius, G. The Relation Between Sustainable Project Management and Project Success. Relation 2020, 9, 218-238. [CrossRef]

16. Martens, M.L.; Carvalho, M.M. Key factors of sustainability in project management context: A survey exploring the project managers' perspective. Int. J. Proj. Manag. 2017, 35, 1084-1102. [CrossRef]

17. Silvius, G.; Schipper, R. Developing a maturity model for assessing sustainable project management. J. Mod. Proj. Manag. 2015, 3.

18. Irfan, M.; Hassan, M.; Hassan, N. The effect of project management capabilities on project success in Pakistan: An empirical investigation. IEEE Access 2019, 7, 39417-39431. [CrossRef]

19. Nenni, M.E.; Arnone, V.; Boccardelli, P.; Napolitano, I. How to increase the value of the project management maturity model as a business-oriented framework. Int. J. Eng. Bus. Manag. 2014, 6, 8. [CrossRef]

20. Gareeb, N.; Rwelamila, P.D. Rethinking project management maturity models for the South African power sector. African J. Sci. Technol. Innov. Dev. 2021, 1-15. [CrossRef]

21. Ibbs, C.W.; Kwak, Y.H. Assessing project management maturity. Proj. Manag. J. 2000, 31, 32-43. [CrossRef]

22. Magano, J.; Silvius, G.; Silva, C.S.; Leite, Â. Exploring Characteristics of Sustainability Stimulus Patterns of Project Managers. Sustainability 2021, 13, 4019. [CrossRef]

23. El Khatib, M.; Alabdooli, K.; AlKaabi, A.; Al Harmoodi, S. Sustainable Project Management: Trends and Alignment. Theor. Econ. Lett. 2020, 10, 1276. [CrossRef]

24. Weninger, C.; Huemann, M. Project initiation: Investment analysis for sustainable development. In Banking, Finance, and Accounting: Concepts, Methodologies, Tools, and Applications; IGI Global: 2015; pp. 1-17. Available online: https://www.researchgate.net/ publication/283864139_Project_Initiation_Investment_Analysis_for_Sustainable_Development (accessed on 1 September 2021).

25. Silvius, G. Sustainability as a new school of thought in project management. J. Clean. Prod. 2017, 166, 1479-1493. [CrossRef]

26. Belout, A.; Gauvreau, C. Factors influencing project success: The impact of human resource management. Int. J. Proj. Manag. 2004, 22, 1-11. [CrossRef]

27. Stanitsas, M.; Kirytopoulos, K.; Leopoulos, V. Integrating sustainability indicators into project management: The case of construction industry. J. Clean. Prod. 2021, 279, 123774. [CrossRef]

28. Cai, N.; Zhang, S.-J.; Li, L. Sustainable project management: A balance analysis model of effect. In Proceedings of the 2009 International Conference on Management and Service Science, Beijing, China, 20-22 September 2009; pp. 1-4.

29. Deland, D. Sustainability through project management and net impact. In Proceedings of the PMI Global Congress North America, Orlando, FL, USA, 1 October 2009. 
30. Elkington, J. Towards the sustainable corporation: Win-win-win business strategies for sustainable development. Calif. Manag. Rev. 1994, 36, 90-100. [CrossRef]

31. Fernández-Sánchez, G.; Rodríguez-López, F. A methodology to identify sustainability indicators in construction project management-Application to infrastructure projects in Spain. Ecol. Indic. 2010, 10, 1193-1201. [CrossRef]

32. Silvius, A.; Schipper, R.P. Sustainability in project management: A literature review and impact analysis. Soc. Bus. 2014, 4, 63-96. [CrossRef]

33. Freeman, R.E. Strategic Management: A Stakeholder Approach; Cambridge University Press: Cambridge, UK, 2010.

34. Marnewick, C.; Silvius, G.; Schipper, R. Exploring patterns of sustainability stimuli of project managers. Sustainability 2019, 11, 5016. [CrossRef]

35. Labuschagne, C.; Brent, A.C. Sustainable project life cycle management: The need to integrate life cycles in the manufacturing sector. Int. J. Proj. Manag. 2005, 23, 159-168. [CrossRef]

36. Silva, C.; Magano, J.; Moskalenko, A.; Nogueira, T.; Dinis, M.A.P.; Pedrosa e Sousa, H.F. Sustainable management systems standards (SMSS): Structures, roles, and practices in corporate sustainability. Sustainability 2020, 12, 5892. [CrossRef]

37. Magano, J.; Silva, C.; Figueiredo, C.; Vitória, A.; Nogueira, T.; Pimenta Dinis, M.A. Generation Z: Fitting Project Management Soft Skills Competencies-A Mixed-Method Approach. Educ. Sci. 2020, 10, 187. [CrossRef]

38. Marcelino-Sádaba, S.; González-Jaen, L.F.; Pérez-Ezcurdia, A. Using project management as a way to sustainability. From a comprehensive review to a framework definition. J. Clean. Prod. 2015, 99, 1-16. [CrossRef]

39. Sabini, L.; Muzio, D.; Alderman, N. 25 years of 'sustainable projects'. What we know and what the literature says. Int. J. Proj. Manag. 2019, 37, 820-838. [CrossRef]

40. Mishra, P.; Dangayach, G.S.; Mittal, M.L. An Ethical approach towards sustainable project Success. Procedia Soc. Behav. Sci. 2011, 25, 338-344. [CrossRef]

41. Silvius, G.; Schipper, R. Exploring variety in factors that stimulate project managers to address sustainability issues. Int. J. Proj. Manag. 2020, 38, 353-367. [CrossRef]

42. Magano, J.; Silvius, G.; Silva, C.S.E.; Leite, Â. The contribution of project management to a more sustainable society: Exploring the perception of project managers. Proj. Leadersh. Soc. 2021, 2, 100020. [CrossRef]

43. Sabini, L.; Alderman, N. The Paradoxical Profession: Project Management and the Contradictory Nature of Sustainable Project Objectives. Proj. Manag. J. 2021, 52, 87569728211007660. [CrossRef]

44. Hacking, T.; Guthrie, P. A framework for clarifying the meaning of Triple Bottom-Line, Integrated, and Sustainability Assessment. Environ. Impact Assess. Rev. 2008, 28, 73-89. [CrossRef]

45. Eskerod, P.; Huemann, M. Sustainable development and project stakeholder management: What standards say. Int. J. Manag. Proj. Bus. 2013. [CrossRef]

46. Ugwu, O.O.; Kumaraswamy, M.M.; Wong, A.; Ng, S.T. Sustainability appraisal in infrastructure projects (SUSAIP): Part 2: A case study in bridge design. Autom. Constr. 2006, 15, 229-238. [CrossRef]

47. Corder, G.D.; McLellan, B.C.; Green, S. Incorporating sustainable development principles into minerals processing design and operation: SUSOP ${ }^{\circledR}$. Miner. Eng. 2010, 23, 175-181. [CrossRef]

48. Labuschagne, C.; Brent, A.C. An industry perspective of the completeness and relevance of a social assessment framework for project and technology management in the manufacturing sector. J. Clean. Prod. 2008, 16, 253-262. [CrossRef]

49. Andersen, E.S.; Jessen, S.A. Project Maturity in Organisations. Int. J. Proj. Manag. 2003, 21, 457-461. [CrossRef]

50. Tahri, H.; Drissi-Kaitouni, O. New design for calculating project management maturity (PMM). Procedia Soc. Behav. Sci. 2015, 181, 171-177. [CrossRef]

51. Morris, A.; Wilkinson, S.; Algeo, C.; Candusso, D. Project Management Maturity Levels. J. Mod. Proj. Manag. 2020, 8, 158-166 [CrossRef]

52. Kerzner, H. Using the Project Management Maturity Model: Strategic Planning for Project Management, 3rd ed.; John Wiley \& Sons: Hoboken, NJ, USA, 2019.

53. Cooke-Davies, T.J. Maturity and measurement what are the relevant questions about maturity and metrics for a project-based organization to ask, and what do they imply for project management research. In Proceedings of the PMI Research Conference, London, UK, 2004.

54. Kwak, Y.H.; Ibbs, C.W. Calculating project management's return on investment. Proj. Manag. J. 2000, 31, 38-47. [CrossRef]

55. Mani, M.; Lyons, K.; Sriram, R. Developing a sustainability manufacturing maturity model. In Proceedings of the IMS Summer School on Sustainable Manufacturing, Zurich, Switzerland, 26-28 May 2010; pp. 311-321.

56. Ashrafi, M.; Adams, M.; Walker, T.R.; Magnan, G. How corporate social responsibility can be integrated into corporate sustainability: A theoretical review of their relationships. Int. J. Sustain. Dev. World Ecol. 2018, 25, 672-682. [CrossRef]

57. Maurício, S.; Rebêlo, I.; Madeira, C.; Resende, F.; Esteves, S. Validation of the Portuguese version of Amsterdam Preoperative Anxiety and Information Scale (APAIS). Health Qual. Life Outcomes 2021, 19, 1-9. [CrossRef] [PubMed]

58. Bolat, B.; Kuşdemir, A.; Uslu, İ.C.; Temur, G.T. An assessment for IT project maturity levels. Int. J. Inf. Technol. Proj. Manag. IJITPM 2017, 8, 1-16. [CrossRef]

59. Hernández, F.Y.; Laguado, R.I.; Rodriguez, J.P. Maturity analysis in project management in Colombian universities. J. Phys. Conf. Ser. 2018, 1126, 012055. [CrossRef] 
60. Spalek, S. Finding a new way to increase project management efficiency in terms of time reduction. Inz. Ekon. Eng. Econ. 2014, 25, 538-548. [CrossRef]

61. Alvarez-Dionisi, L.E.; Turner, R.; Mittra, M. Global Project Management Trends. Int. J. Inf. Technol. Proj. Manag. 2016, 7, 54-73. [CrossRef] 